\title{
Quantitative Detection of In-Service Strength of Underground Space Strata considering Soil-Water Interaction
}

\author{
Xiangfeng $L v \mathbb{D}^{1,2}$ and Hongyuan Zhou $\mathbb{D}^{3}$ \\ ${ }^{1}$ School of Civil and Resource Engineering, University of Science \& Technology Beijing, Beijing 100083, China \\ ${ }^{2}$ Beijing Key Laboratory of Urban Underground Space Engineering, University of Science \& Technology Beijing, \\ Beijing 100083, China \\ ${ }^{3}$ Key Laboratory of Ministry of Education on Safe Mining of Deep Metal Mines, College of Resources and Civil Engineering, \\ Northeastern University, Shenyang, 110819, China
}

Correspondence should be addressed to Hongyuan Zhou; zhouhongyuan2016@163.com

Received 19 July 2019; Accepted 4 January 2020; Published 7 February 2020

Academic Editor: Yinshan Tang

Copyright @ 2020 Xiangfeng Lv and Hongyuan Zhou. This is an open access article distributed under the Creative Commons Attribution License, which permits unrestricted use, distribution, and reproduction in any medium, provided the original work is properly cited.

\begin{abstract}
The in-service strength test of underground space strata is a hot issue in geotechnical engineering. In this study, we conducted mechanical analyses on the soil and the cutting bit involved in a rotary drilling process, which revealed the key factors influencing drilling. This allowed us to establish theoretical relationships among torque, propulsion, and soil strength parameters (i.e., unconfined compressive strength, shear strength, and cohesion). Moreover, with consideration of the effects of water content and geostatic stresses, we used an independently developed rotary drilling system with a 3D flexible boundary loading device to conduct 75 rotary drilling model indoor tests on silty clay in 15 groups. Based on the test results, we simplified the theoretical relationships and determined model parameters to obtain 15 quantitative relationships with 5 different water contents $(4.8 \%$, $9.7 \%, 14.8 \%, 19.6 \%$, and $24.9 \%$ ). Finally, through field application, we verified the quantitative relationships and we discussed their scope of application. The results showed it is feasible to predict the soil in-service strength based on rotary drilling parameters. Under the premise that water content is considered, the drilling parameters were found correlated linearly (correlation coefficients are all greater than 0.85 ) with strength parameters. In field application, absolute errors between the prediction and investigation results were less than $5 \%$, satisfying engineering requirements.
\end{abstract}

\section{Introduction}

The in-serve strength of the strata refers to the effective strength that the underground rock and soil can provide during the operation of the underground structure. Currently, methods for testing soil in-serve strength include cone penetration tests, drop penetration tests, plate load tests, pressuremeter tests, and vane shear tests, from which strength parameters such as bearing capacity, shear strength, cohesion, and angle of internal friction can be obtained [1]. In addition, the combined drilling core indoor test, which is another important method used for evaluation of in situ soil strength, has been applied widely in real engineering projects. Its advantage lies in its capacity to provide the most direct and accurate information for determining the soil type and extracting stratigraphic characteristics, allowing the acquisition of various physical and mechanical parameters that serve as reference for in situ strength evaluation. Therefore, conducting soil strength parameter testing during the drilling process is of great interest because it would reduce the workload associated with the indoor test, while retaining the aforementioned advantage of core drilling.

Establishing relationships between the physical and mechanical parameters of soils and MWD (measurementwhile-drilling) parameters could effectively resolve the problem caused by the separation of the core drilling and indoor test. The rapid development in recent years of the MWD technique has been marked by many achievements in terms of theory, experiment, and field application. Theoretical drilling mechanics models have been developed for 
various drill bits, including roller bits, impact bits, cutting bits, and polycrystalline diamond compact bits [2-8]. Experimentally, the relationships among drilling parameters (e.g., torque, propulsion, revolution speed, and penetration rate) have been studied [9-11], while the relationships between drilling parameters and rock physics as well as mechanical parameters (i.e., stiffness, cohesion force, shear strength, and density) have been revealed [12-15]. In terms of field applications, evaluations of rock grades, investigations of rock rupture regions, and evaluations of the drillability of rock and rock-like materials have been conducted [16-22]. However, previous studies have focused mostly on rock MWD responses, whereas research on MWD soil tests is still lacking.

This paper presents a theoretical model suitable for soil rotary drilling with an analysis of the key factors affecting the performance of the cutting bit when drilling into the soil. Using silty clay widely available from the Beijing area (China) as an example case, we used an independently developed the rotary drilling system with a 3D flexible boundary loading device to conduct rotary drilling model tests under different water contents and conditions. Based on the derived experimental results, we established quantitative relationships for torque and propulsion with unconfined compressive strength (UCS), shear strength, and cohesion. We verified these relationships in field applications and we ascertained their scope of application.

\section{Rotary Drilling Mechanics Model}

2.1. Force Analysis on Soil during Shearing Process. Based on the working process of the cutting bit on the soil $[13,23]$, we constructed a cutting model, as shown in Figure 1. To analyze the stress distribution on the shear plane, we assumed the soil as a wedge with its top corner as angle $2 \alpha$, and we simplified the uniform load as a point load $P$ and an equivalent couple $M(M=P h \cos \varphi / 2 \cos \gamma)$ acting on the top corner of the wedge.

We set the origin at the top corner of the wedge, using the wedge symmetry axis as the $X$ axis in an orthogonal coordinate system or as the polar axis in a polar coordinate system, where $\theta$ in the anticlockwise direction is positive. We defined the inclination angle as $\gamma$, cutting depth as $h$, angle between the shear plane and cutting plane as $\psi$, angle between point load $P$ and the wedge symmetry axis as $\beta$, angle between point load $P$ and the normal vector of the inclined plane as $\varphi$, and friction coefficient between the tooth face and the soil shear plane as $\mu$ (where $\tan \varphi=\mu$ and $\beta=\pi /(2-\alpha-\varphi))$. Hence, the stress on the wedge could be calculated as follows:

$$
\left\{\begin{array}{l}
\sigma_{r}=\left(\sigma_{r}\right)_{P}+\left(\sigma_{r}\right)_{M}=-\frac{2 P}{r}\left(\frac{\cos \beta \cos \theta}{2 \alpha+\sin 2 \alpha}+\frac{\sin \beta \sin \theta}{2 \alpha-\sin 2 \alpha}\right)+\frac{2 M \sin 2 \theta}{(\sin 2 \alpha-2 \alpha \cos 2 \alpha) r^{2}} \\
\sigma_{\theta}=\left(\sigma_{\theta}\right)_{P}+\left(\sigma_{\theta}\right)_{M}=0, \\
\tau_{r \theta}=\left(\tau_{r \theta}\right)_{P}+\left(\tau_{r \theta}\right)_{M}=-\frac{M(\cos 2 \theta-\cos 2 \alpha)}{(\sin 2 \alpha-2 \alpha \cos 2 \alpha) r^{2}} .
\end{array}\right.
$$

We rotated the original coordinate system $X O Y$ in the clockwise direction by angle $\eta$, such that in the newly obtained coordinate system $X^{\prime} O^{\prime} Y^{\prime}$, the $X^{\prime}$ axis is perpendicular and the $Y^{\prime}$ axis is parallel to the shear plane. We then transformed the stress components in equation (1) to those in the $X^{\prime} O^{\prime} Y^{\prime}$ coordinate system. With $\eta=(\pi / 2-\alpha-\psi)$ and $\xi=\theta+\eta$, the stress components in the polar coordinate system can be transformed to those in the $X^{\prime} O^{\prime} Y^{\prime}$ orthogonal coordinate system.

On the contact plane between the drill bit and the soil, both normal pressure and friction are at work. Assuming the internal friction angle is $\phi$, normal pressure is distributed evenly and the resultant force is $P_{1}$. Thus, the reaction force from the soil is $P_{2}$ and the shear reaction force is $T_{2}$, with the shear plane at angle $\psi$ from the cutting plane, as shown in Figure 2.

It is assumed the stress on the shear plane satisfies the Mohr-Coulomb yield criterion, and the soil ruptures or yields when $\tau_{X^{\prime} Y^{\prime}}=c+\sigma_{X^{\prime}} \tan \phi$. Under the limit of equilibrium, the force equilibrium equations on the shear plane are

$$
\begin{cases}\sum X=0 & P_{1} \sin (\pi / 2-\gamma-\psi-\varphi)-T_{2}=0 \\ \sum Y=0 & P_{2}-P_{1} \cos (\pi / 2-\gamma-\psi-\varphi)=0\end{cases}
$$
have

Substituting $T_{2}=c s_{1}+P_{2} \tan \varphi$ into equation (2), we

$$
P_{1}=\frac{c s_{1} \cos \phi}{\cos (\gamma+\phi+\varphi+\psi)}
$$

Since $s_{1}=b h / \cos \psi$,

$$
P_{1}=\frac{c b h \cos \phi}{\cos (\gamma+\phi+\varphi+\psi) \cos \psi},
$$

where $h$ is the cutting depth, $b$ is the cutting tooth width, $c$ is cohesion, and $\phi$ is the internal friction angle. Substituting equation (4) into equation (2) gives

$$
T_{2}=\frac{c b h \cos \phi \cos (\gamma+\varphi+\psi)}{\cos (\gamma+\phi+\varphi+\psi) \cos \psi} \text {. }
$$



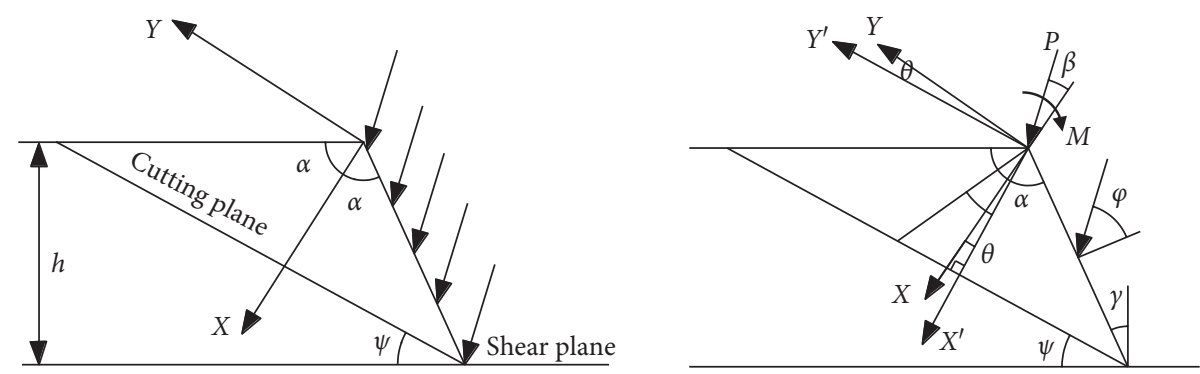

Figure 1: Shear stress analysis of drill bit teeth.

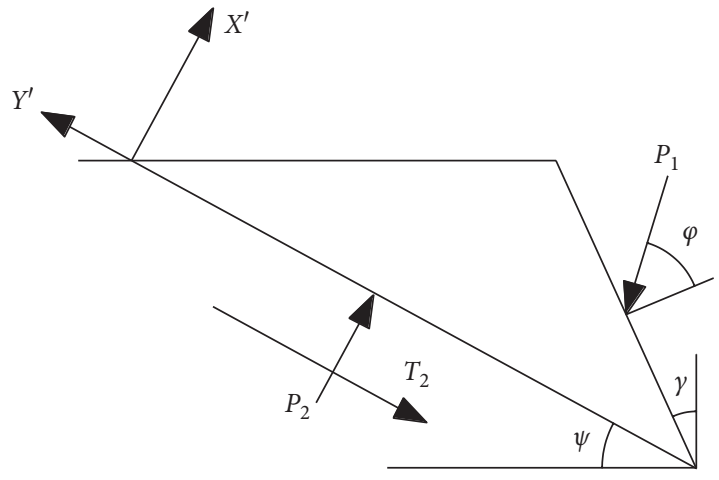

FIgUre 2: Shear body force analysis.

Equation (5) calculates the cutting force on the soil during the drilling process, where $b$ and $\gamma$ are associated with the drill bit shape, while $c, \psi, \varphi$, and $\phi$ are parameters associated with the rock properties.

2.2. Force Analysis on Drill Bit Tooth. Forces acting on a single drill tooth include propulsion $F_{n}^{\prime}$ from the drill rod, cutting force $F_{m}^{\prime}$, resistance from the soil to cutting $F_{1}$, antiincision force $F_{2}$, and frictional resistance $F_{3}$ on the tooth wear surface, where $F_{1}$ and drill force $P_{1}$ acting on the soil constitute a pair of action and reaction forces [7]. The force diagram of a drill tooth is shown in Figure 3.

Hence,

$$
F_{1}=P_{1}=\frac{c b h \cos \phi}{\cos (\gamma+\phi+\varphi+\psi) \cos \psi} .
$$

Here, $F_{2}$ is the normal pressure from the drill tooth acting on the soil and calculated by

$$
F_{2}=b \sigma_{m}\left[\frac{0.6}{\cos \gamma}+\frac{1}{3}\left(l_{f}-\frac{0.6}{\cos \gamma}\right)\right],
$$

where the maximum stress $\sigma_{m}=k \sigma_{s}, k$ is a parameter dependent on the geometric shape of the drill tooth and the friction on the contact surface, $\sigma_{s}$ is the compressive strength of the soil, and $l_{f}$ is the frictional length of the cutting edge.

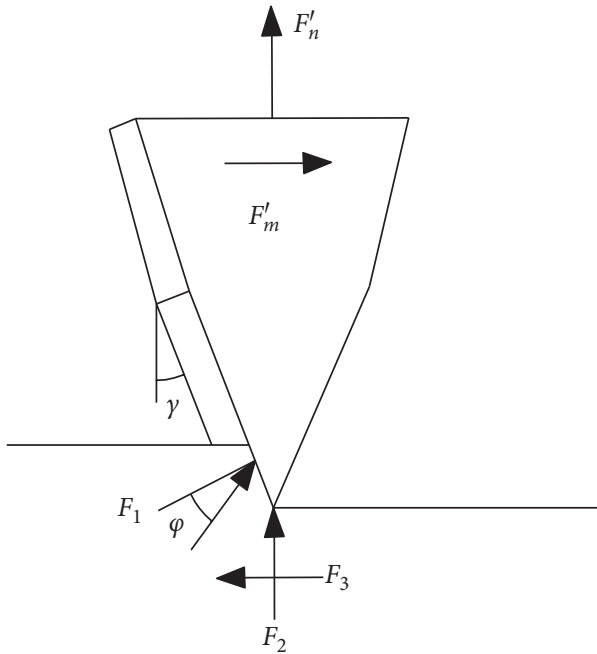

Figure 3: Single drill tooth force diagram.

Thus, $F_{2}$ is correlated with the stress distribution on the frictional surface.

The frictional coefficient between the cutting blade and the soil is $\mu_{1}$; therefore, $F_{3}=\mu_{1} F_{2}$. The force balance equations on the drill bit are

$$
\left\{\begin{array}{l}
F_{n}^{\prime}=F_{1} \sin (\gamma+\varphi)+F_{2}, \\
F_{m}^{\prime}=F_{1} \cos (\gamma+\varphi)+\mu_{1} F_{2} .
\end{array}\right.
$$

As the drill bit is under pressure from the porous soil, the normal pressure $p_{0}$ and frictional torque $M_{1}$ are distributed on its surface [24]. If we assume the frictional coefficient between the porous soil and the drill bit surface is $\mu_{2}$, we have

$$
M_{1}=\mu_{2} \int_{s} p_{0} \cdot R \mathrm{~d} s=\mu_{2} p_{0} \cdot R s,
$$

where $R$ is the radius of the drill bit and $s$ is the contact surface area between a single tooth and the porous soil.

Forces acting on the drill bit include propulsion $F_{n}$ and torque $M_{n}$. Because the drill bit comprises three cutting blades, the balance equations for the drill bit are 


$$
\left\{\begin{array}{l}
F_{n}=3 \frac{c b h \cos \phi}{\cos (\gamma+\phi+\varphi+\psi) \cos \psi} \sin (\gamma+\varphi)+b \sigma_{m}\left(l_{f}+\frac{1.2}{\cos \gamma}\right), \\
M_{n}=\left[3 \frac{c b h \cos \phi}{\cos (\gamma+\phi+\varphi+\psi) \cos \psi} \sin (\gamma+\varphi)+\mu_{1} b \sigma_{m}\left(l_{f}+\frac{1.2}{\cos \gamma}\right)\right] \cdot R^{\prime}+3 \mu_{2} p_{0} R s,
\end{array}\right.
$$

where $R \prime$ is the equivalent radius of the drill bit. From equation (10), we can conclude that $F_{n}$ and $M_{n}$ are correlated with the soil properties and drill bit parameters. When given the soil type, key physical parameters, geometric parameters of the drill bit and rod, and drilling speed as well as drilling rod revolution speed, conducting an indoor test allows us to obtain the quantitative relationship between torque, propulsion, and soil strength parameters [25].

\section{Material and Method}

3.1. Material Characterization. We selected a soil sample at a certain foundation pit for the test, according to the geotechnical test standards in ASTM [26]. The obtained soil sample had natural water content of $18.4 \%$, dry density of $1.83 \mathrm{~g} \cdot \mathrm{cm}^{-3}$, liquid limit of $25.7 \%$, plastic limit of $14.5 \%$, porosity of 0.70 , and specific gravity of 2.71 . The gradation curve of the base soil sample is shown in Figure 4. According to the soil classification standard ASTM [26], we can determine that the test sample is silty clay.

\subsection{Rotary Drilling Test}

3.2.1. Test Device. The rotary drilling system used in this study is shown in Figure 5. The system comprised the rig body, computer and system software, a data receiver, and a gasoline engine, with a torque sensor that measures up to $200 \mathrm{~N} \cdot \mathrm{m}$ and a maximum revolution speed of $800 \mathrm{r} / \mathrm{min}$. The computer and system software process the data in real time, calculating the penetration rate and plotting graphs that show the relationships between torque, propulsion, revolution speed, and drilling depth.

The flexible boundary loading device simulates the stress due to the weight of the soil by applying confining pressure, as shown in Figure 6. The device comprised (1) a servocontrolled hydraulic pump, (2) flexible boundary loading device, and (3) hydraulic jack. The hydraulic jack provides pressure, the flexible boundary loading device transmits the pressure, and the hydraulic pump controls the loading rate. Two hydraulic jacks separated by a distance of $80 \mathrm{~cm}$ act on each of the flexible loading plates (each $100 \times 100 \mathrm{~cm}$ ). A $120 \mathrm{~cm}$ long I-beam provides the reaction force. The maximum compressive stress that could be applied by the flexible boundary loading device is $4 \mathrm{MPa}$ at a maximum loading rate of $0.01 \mathrm{MPa} / \mathrm{s}$. The connections between the I-beam, jacks, and flexible loading plates are shown in Figure 6 (2-1), and the connections between the loading plates are shown in Figure 6 (2-2).
3.2.2. Sample Preparation and Key Parameters. The method adopted for sample preparation was the same as Lv et al. [27]. The samples were designed to contain water contents of $5 \%, 10 \%, 15 \%, 20 \%$, and $25 \%$ with a dry density of $1.83 \mathrm{~g} \cdot \mathrm{cm}^{-3}$. To ensure test accuracy, the water content of the samples required reassessment immediately prior to performing the tests. The tests used sharp-tooth composite drill bits (Figure 4) that had outer and inner diameters of 5.5 and $5.0 \mathrm{~cm}$, respectively. The drilling confining pressures were 0 , $100,200,300$, and $400 \mathrm{kPa}$, with revolution speed of $500 \mathrm{r} /$ min, penetration rate of $15 \mathrm{~cm} / \mathrm{min}$, and drilling depth of $90 \mathrm{~cm}$.

3.3. Soil Strength Test. We used a fully automatic triaxial test apparatus (Product Model TSZ-1, Nanjing Soil Equipment Factory, China) to conduct the UCS test and the triaxial shear test. The test samples, which were $50 \mathrm{~mm}$ in diameter and $100 \mathrm{~mm}$ in height, were prepared according to the following procedure.

When a core obtained from drilling satisfied the sample preparation requirement, i.e., the overall size was larger than the sample size, a cylinder $(50 \mathrm{~mm}$ diameter and $100 \mathrm{~mm}$ height) was cut out as the test sample. When using a core for sample preparation, it was necessary to maintain its density and to keep the water content uniform by adopting an undercompaction procedure [28]. During the tests, the loading rate was $0.8 \mathrm{~mm} / \mathrm{min}$ and the confining pressures were $0,100,200,300$, and $400 \mathrm{kPa}$. When the strain reached $16 \%$, the test was halted and either the peak point of the stress-strain curve or the stress at $15 \%$ strain was chosen as the sample strength [29].

\section{Test Results and Discussion}

4.1. Data Processing and Statistics. Based on the previous study [30], data falling into the following five categories were considered invalid: (1) negative torque or propulsion, (2) sudden increase or decrease in torque or propulsion when the magnitude of change exceeds $20 \%$ of the average value, (3) decreased drilling depth, (4) sudden increase or decrease in penetration rate when the magnitude of change exceeds $5 \%$ of the average value, and (5) sudden decrease in revolution speed when the magnitude of change exceeds $5 \%$ of the average value.

4.2. Mechanical Parameters under Different Water Content and Confining Pressure. The patterns of how the UCS, shear strength, cohesion, and internal friction angle are influenced by water content and confining pressure are shown in Figures $7(\mathrm{a})-7(\mathrm{~d})$, respectively. From the plots, we can 


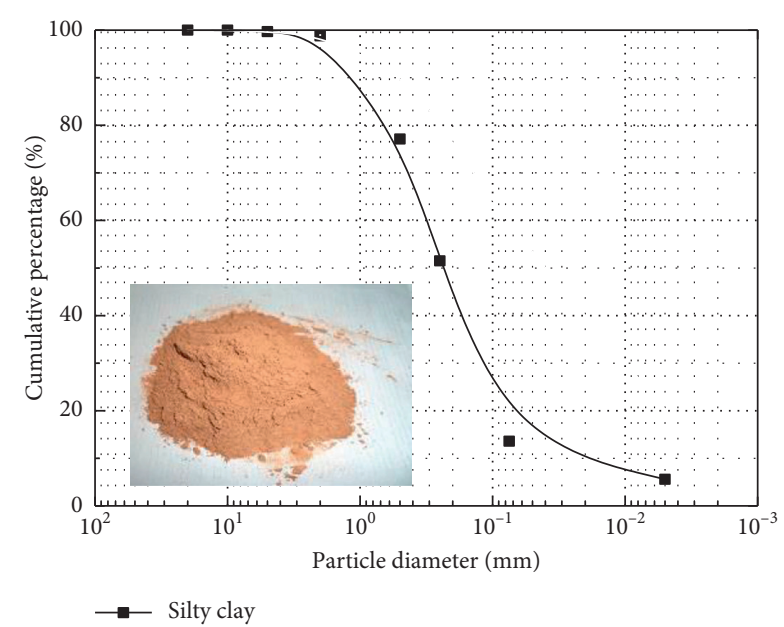

FIgURe 4: Gradation curve of the base soil.

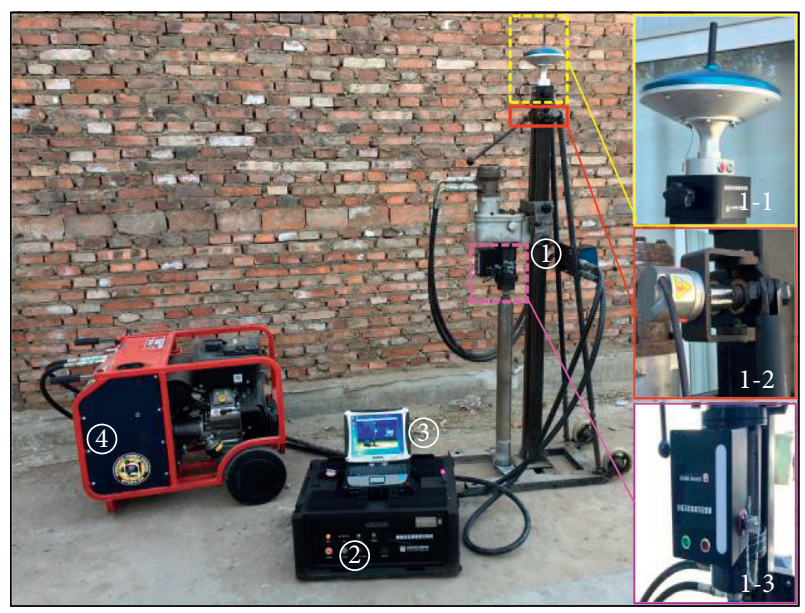
(1) Rig body
(3) Data receiver
(2) Computer and system software
(4) Gasoline engine

Figure 5: Drilling system.

conclude that at constant confining pressure, increased water content resulted in distinctively reduced UCS, shear strength, and cohesion. Conversely, under constant water content, increased confining pressure resulted in increased UCS, shear strength, and cohesion. Regardless of the changes in confining pressure and water content, internal friction angle did not exhibit obvious change; instead, it remained reasonably constant at $28^{\circ}-33^{\circ}$. The reasons behind the above conclusions are as follows. As water content increases, interaction among soil particles decreases, which causes UCS and cohesion to decrease. Ultimately, reduced cohesion causes shear strength to decrease. Conversely, confining pressure is able to change the soil structure. Thus, as it increases, soil compactness also increases, and this causes UCS, cohesion, and shear strength to increase [31].

\subsection{Rotary Drilling Parameters under Different Water Content} and Confining Pressure. The patterns of how the drilling

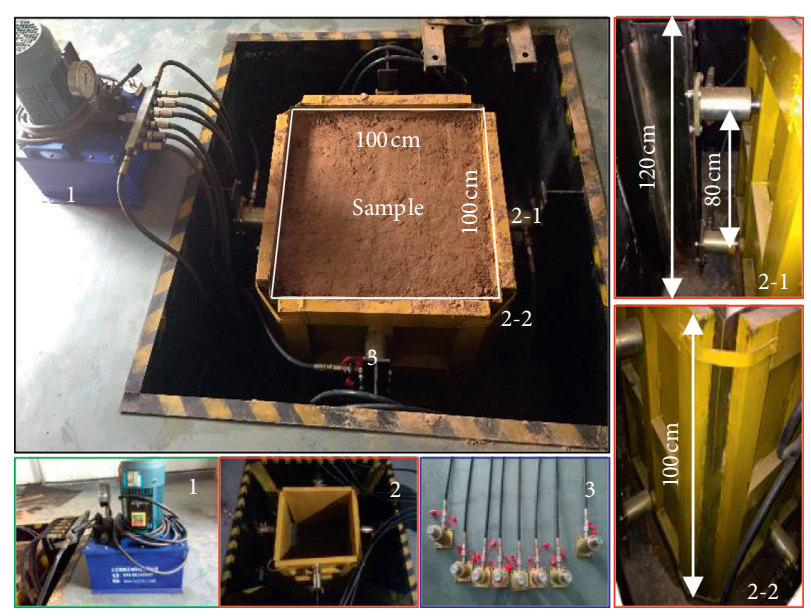

FIgURE 6: Flexible boundary loading device.

parameters are influenced by water content and confining pressure are shown in Figure 8. It can be concluded from Figures $8(\mathrm{a})$ and $8(\mathrm{~b})$ that under constant confining pressure, increased water content causes torque and propulsion to decrease, whereas with constant water content, increased confining pressure causes torque and propulsion to increase. The changes in drilling parameters are due to the following reasons. As water content increases, soil strength decreases because the water serves as lubricant, reducing the frictional coefficient between the drill bit and the soil. As confining pressure increases, soil compactness and strength both increase. Thus, interaction between the drill bit and the soil increases, causing torque and propulsion to increase as well. From the analysis above, we can conclude that drilling parameters increase or decrease simultaneously with soil strength, proving that changes in MWD parameters can reflect soil strength, thus providing a key foundation for establishing quantitative relationships between MWD parameters and soil strength.

\subsection{Correlation between Rotary Drilling Parameters and Mechanical Parameters}

4.4.1. Simplification of Relationships between Drilling Parameters and Mechanics Parameters. Mirabile discovered that while using a cutting bit for drilling into a rock-soil body [9], propulsion is used mostly to overcome the UCS, whereas torque used is mostly to overcome the shear strength of the rock-soil body. Combining this understanding with the theoretical analysis and test results derived from our research, and under the premise of considering or not considering water content, we established separate sets of quantitative relationships between propulsion and UCS, between torque and shear strength, and between torque and cohesion. For these, linear relationships are preferred as long as accuracy is preserved [13].

4.4.2. Correlation between Propulsion and UCS. The quantitative relationships between propulsion and UCS under different water contents are shown in Figure 9(a). From the plot, we can conclude that propulsion is linearly 


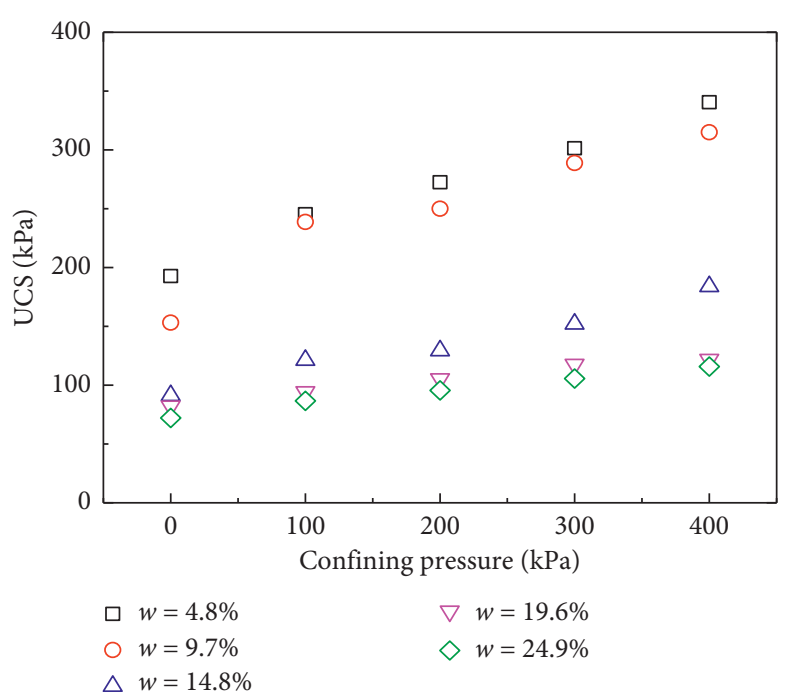

(a)

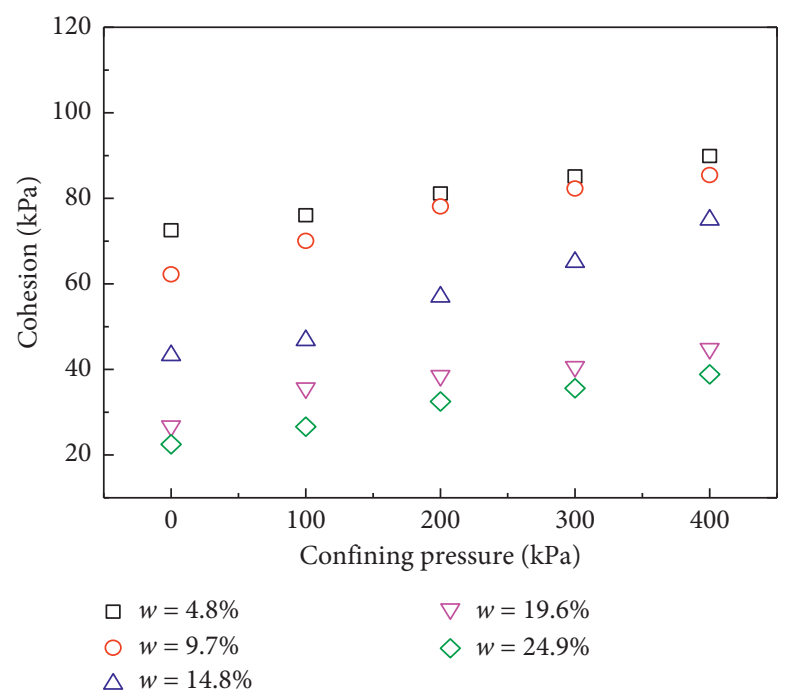

(c)

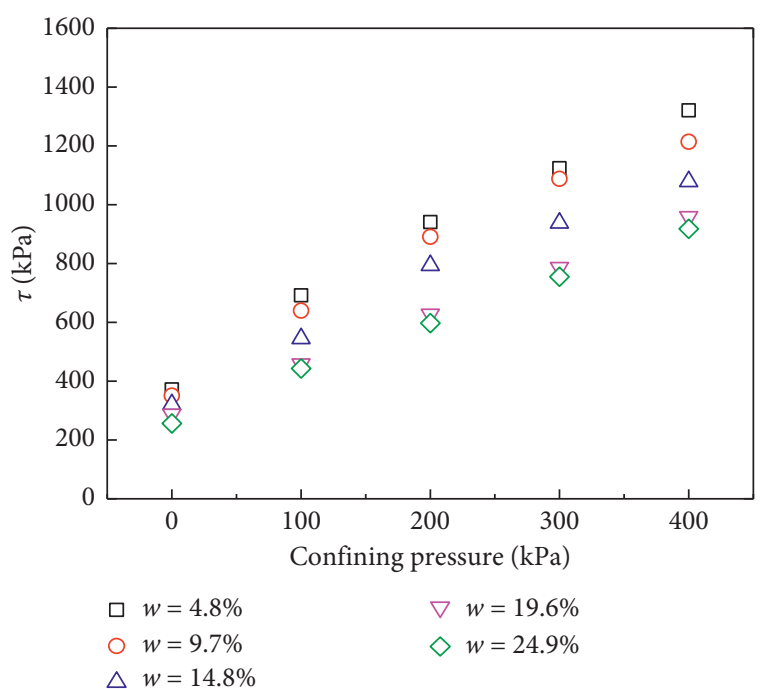

(b)

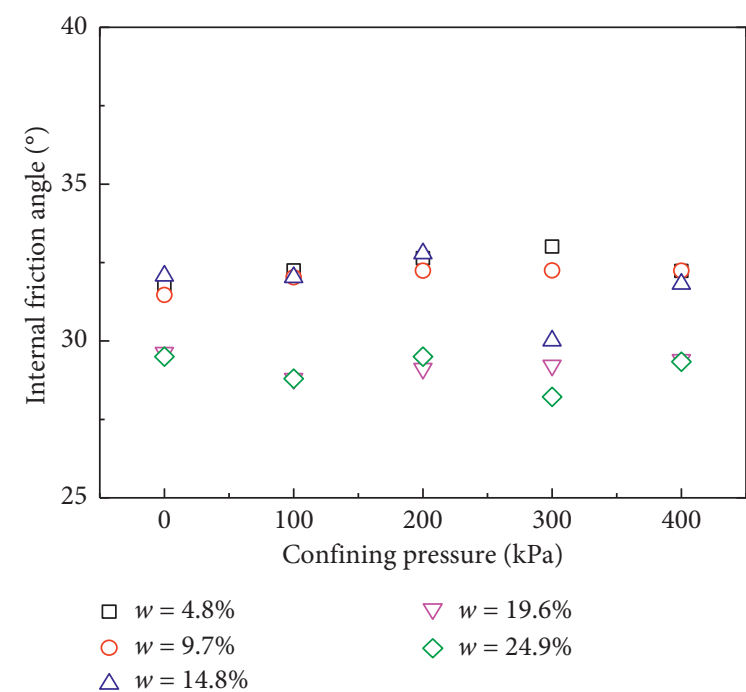

(d)

Figure 7: Patterns in changes of mechanical parameters under the influence of water content and confining pressure: (a) unconfined compressive strength (UCS), (b) shear strength, (c) cohesion, and (d) internal friction angle.

proportional (correlation coefficients are all great than 0.90 ) to UCS for water contents of $4.8 \%-24.9 \%$. The decreasing slope in the linear fitting formula shows that the effects of water content and confining pressure on UCS decrease. When water content increases to a threshold (about 20\%), UCS tends toward stability. From Figure 9(b), we can conclude that without considering the effect of water content, the relationship between propulsion and UCS can be described by the exponential function $\mathrm{UCS}=1.15 T_{h}^{3.27}$ (correlation coefficient $=0.898)$. Through comparison of Figures 9(a) and 9(b), we can conclude that taking water content into consideration enhances the accuracy of the quantitative relationship between propulsion and UCS.

4.4.3. Correlation between Torque and Shear Strength. The correlation between shear strength and torque is shown in Figures 10(a) and 10(b). From Figure 10(a), we can conclude that a linear relationship between torque and shear strength is evident (correlation coefficients are all great than 0.95) when taking water content into consideration. Moreover, as water content increases, the slope in the fitting equation initially increases and then decreases. The reason for this is that shear strength is affected by both water content and confining pressure. When the water content is reasonably low (below 20\%), an increase in confining pressure causes torque and shear strength to increase at an increasing rate, which causes the slope to increase. However, when the water content is reasonably high, the effect of confining pressure on shear strength is reduced. As the confining pressure increases, shear strength and torque both increase at a decreasing rate, which causes the slope to decrease. From Figure 10(b), we can conclude that without considering water content, the relationship between shear strength and torque (correlation coefficient $=0.852$ ) can be represented by $\tau=5074.07 \ln (0.35 \ln (\mathrm{T}))$. Through 


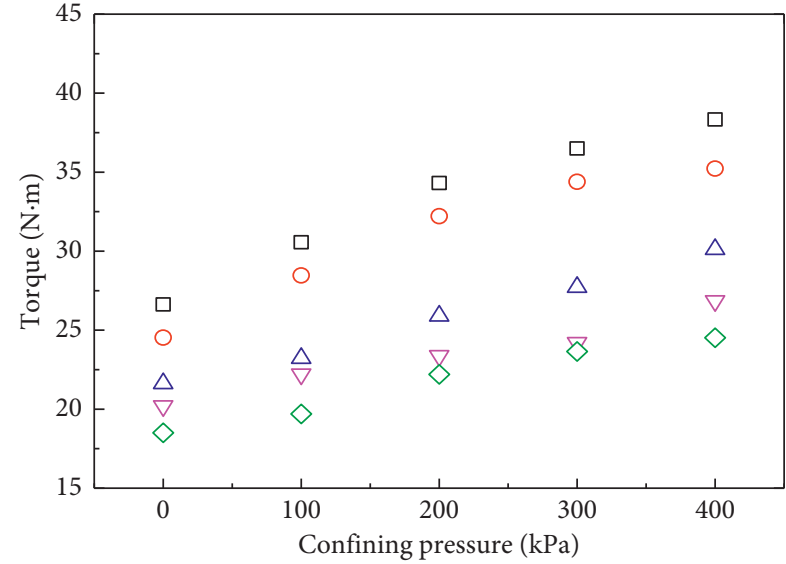
ㅁ $w=4.8 \%$
○ $w=9.7 \%$
$\nabla w=19.6 \%$
$\diamond w=24.9 \%$

$\triangle w=14.8 \%$

(a)

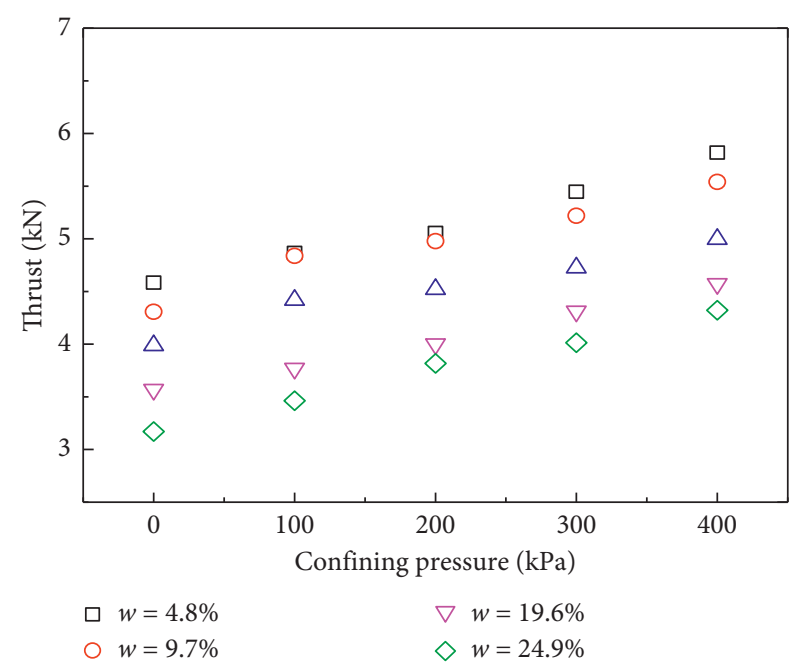

(b)

Figure 8: Patterns in changes of rotary drilling parameters under influence of water content and confining pressure: (a) torque and (b) propulsion.

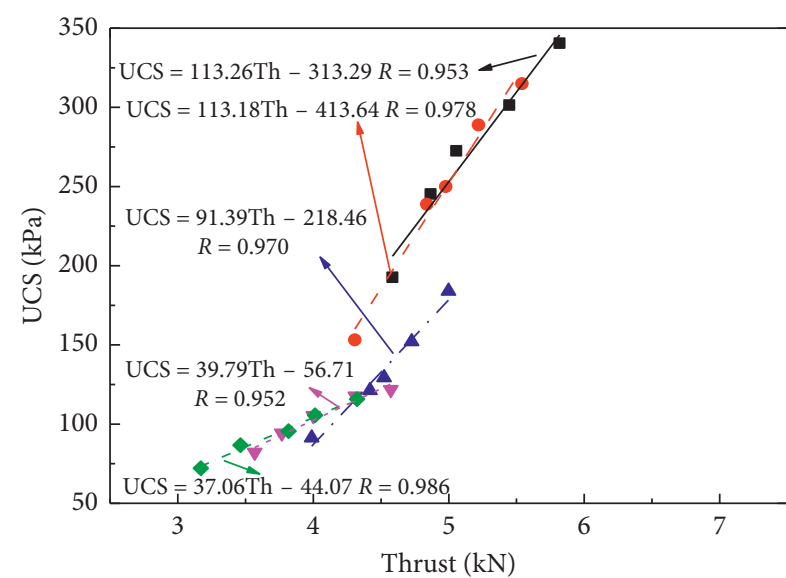

- Test results $(w=4.8 \%) \quad$ Fitting curve $(w=4.8 \%)$

- Test results $(w=9.7 \%) \quad$ - Fitting curve $(w=9.7 \%)$

- Test results $(w=14.8 \%)-$ - Fitting curve $(w=14.8 \%)$

$\checkmark$ Test results $(w=19.6 \%) \quad \ldots$ Fitting curve $(w=19.6 \%)$

Test results $(w=24.9 \%)-\cdots$ Fitting curve $(w=24.9 \%)$

(a)

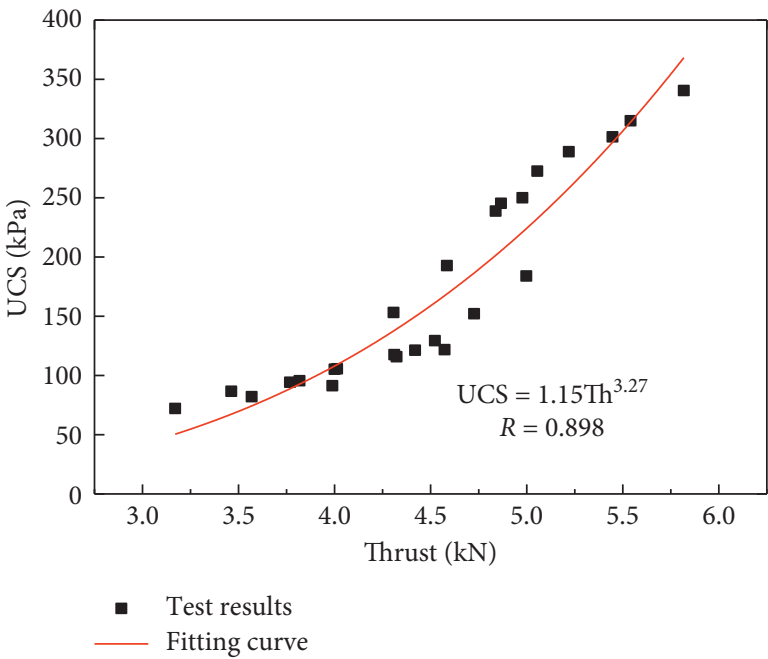

(b)

FIGURE 9: Relationship between propulsion and UCS: (a) considering water content and (b) without considering water content.

comparison of Figures 10(a) and 10(b), we can conclude that taking water content into consideration enhances the accuracy of the quantitative relationship between torque and shear strength.

4.4.4. Correlation between Torque and Cohesion. The relationship between torque and cohesion is shown in Figures 11(a) and 11(b). From Figure 11(a), we can conclude that torque is linearly proportional to cohesion at different water contents (correlation coefficients are all great than 0.90). From Figure 11(b), we can conclude that the relationship between torque and cohesion (correlation coefficient $=0.898$ ) can be represented by $C=331.41 \ln (0.362 \ln (\mathrm{T}))$, when not taking water content into consideration. The pattern of change observed in the slope of the line of best fit for the torque-cohesion relationship is the same as for torque-shear strength, i.e., when the internal friction angle settles within $28^{\circ}-32^{\circ}$, changes in cohesion correspond to changes in shear strength. Through comparison of Figures 11(a) and 11(b), we can conclude that taking water content into consideration enhances the accuracy of the quantitative relationship between torque and cohesion. 


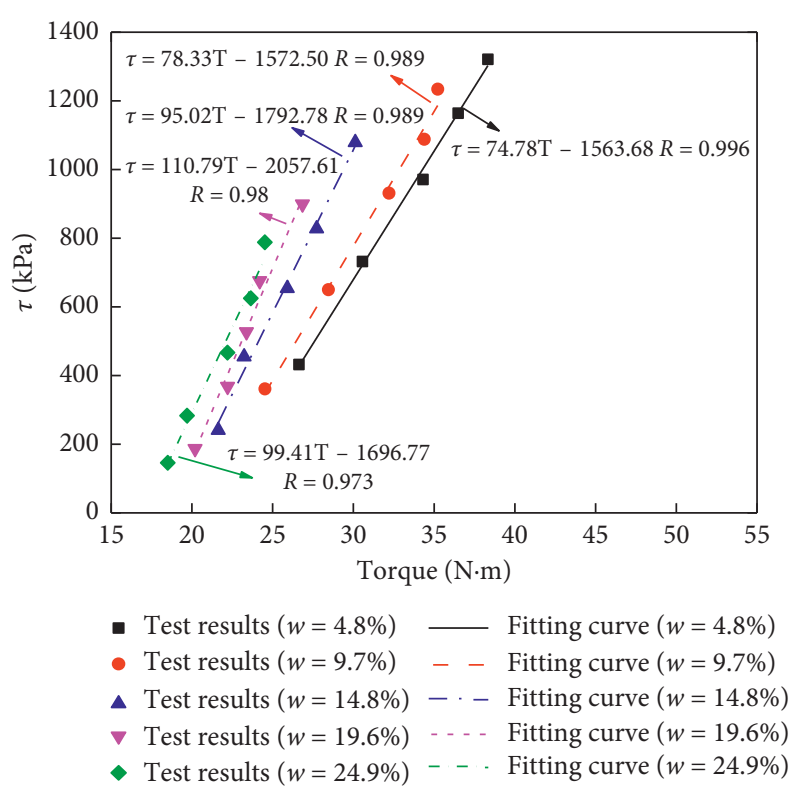

(a)

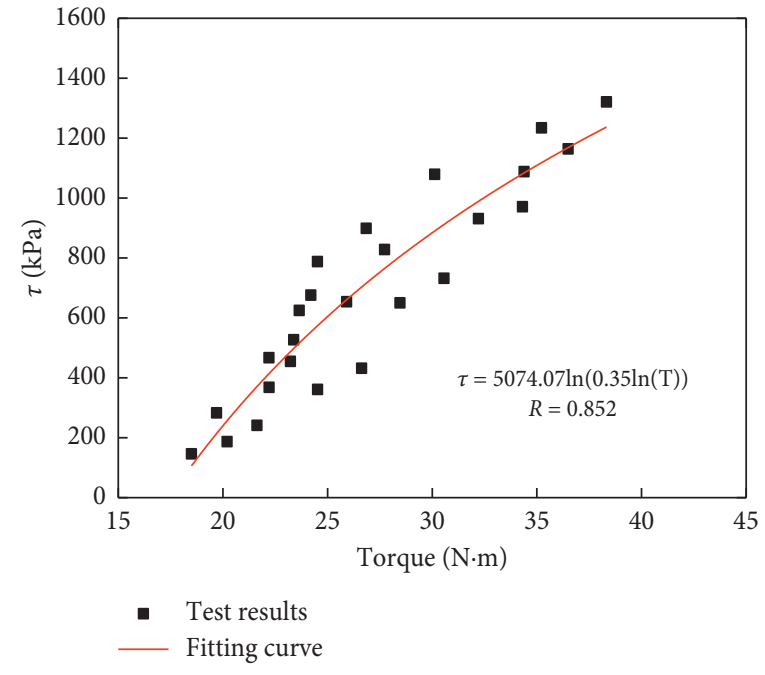

(b)

FiguRE 10: Relationship between torque and shear strength: (a) considering water content and (b) without considering water content.

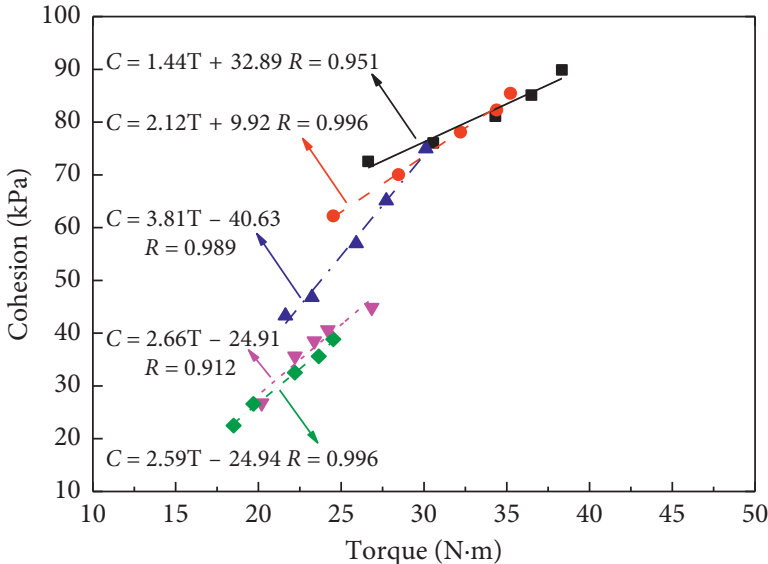

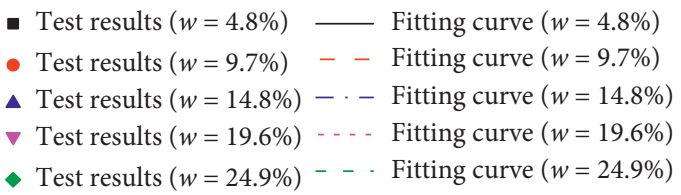

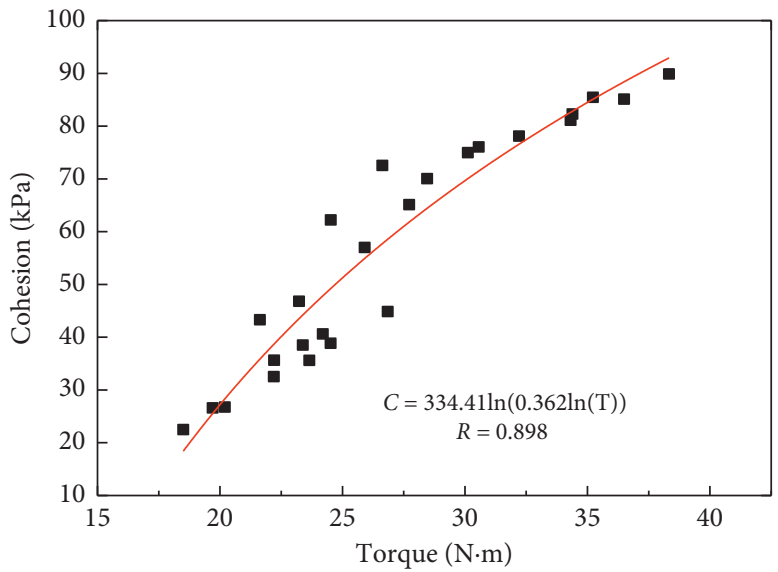

- Test results Fitting curve

FIGURE 11: Relationship between torque and cohesion: (a) considering water content and (b) without considering water content.

\section{Field Application}

5.1. Test Conditions. The field test was conducted at a common trench construction site in Yanqing District, Beijing, China. Geological explorations revealed that up to depths of $21.0 \mathrm{~m}$, the strata could be divided between manmade accumulation and quaternary deposits. The layer of man-made accumulation had a buried depth of 0.70-1.90 m, beyond which was the layer of quaternary deposits. At the buried depth of $10.0-11.0 \mathrm{~m}$, phreatic-piestic water was discovered. As part of the construction project, excavation was undertaken on the layer of man-made accumulation, which revealed that the material in the depth range of 0.0-6.8 $\mathrm{m}$ consisted of silty clay. Because the soil properties in the field test were found the same as those of the indoor drilling test and because the water table was reasonably relatively low, the site was considered appropriate for a field rotary drilling test.

5.2. Rotary Drilling Test Results. The field rotary drilling test used a cutting bit with outer and inner diameters of 5.5 and 


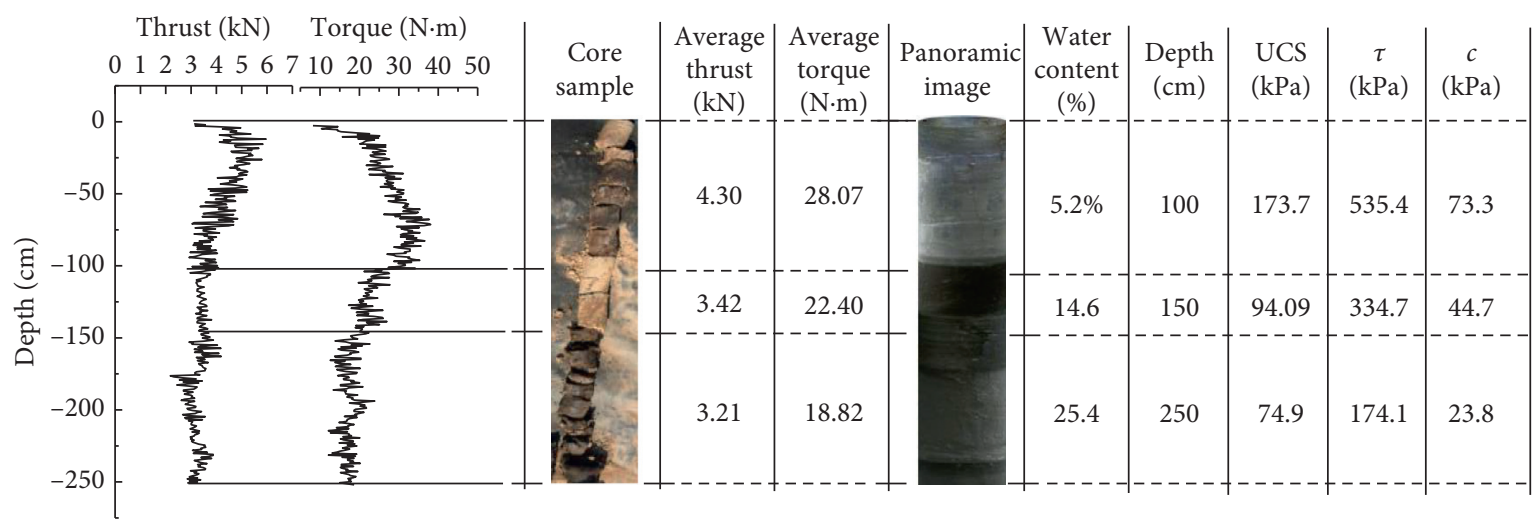

FIgURE 12: Comprehensive data of the rotary drilling test.

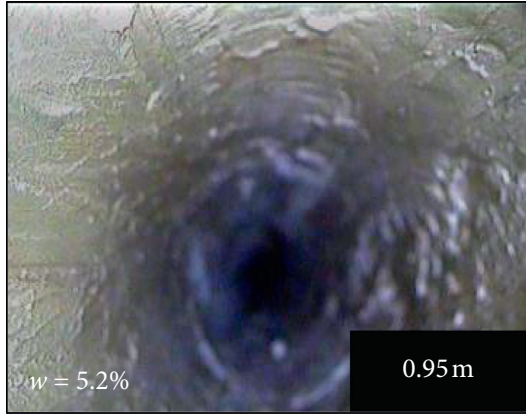

(a)

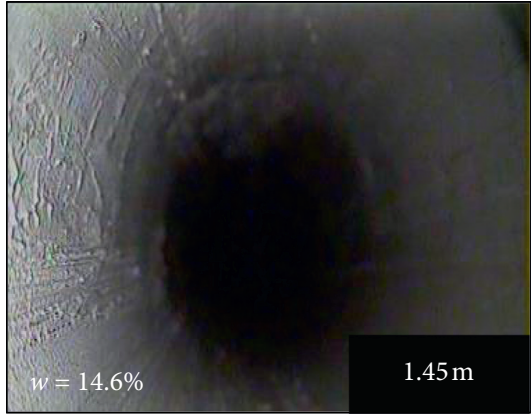

(b)

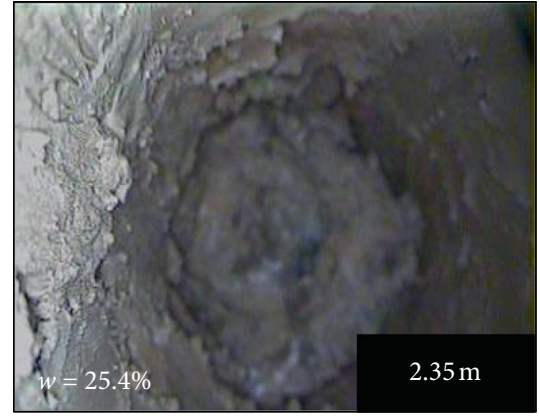

(c)

Figure 13: Cross sections of inner-wall surface of the drilled hole.

$5.0 \mathrm{~cm}$, respectively, at a revolution speed of $500 \mathrm{r} / \mathrm{min}$, penetration rate of $15 \mathrm{~cm} / \mathrm{min}$, and drilling depth of $2.5 \mathrm{~m}$. After the rotary drilling test was completed, the morphology of drilled hole was obtained using the TS-C1201(B) panoramic borehole camera system. Combining this information with in situ core sampling and a drilling performance curve, we divided the soil according to depth. After selecting the rotary drilling test data in accordance with the method introduced in Section 4.1, we calculated the average torque and propulsion within each depth range. Taking water content into consideration, we used the derived fitting equations to calculate the soil mechanical parameters. Figure 12 shows comprehensive data of the rotary drilling test. Figure 13 shows cross sections of the inner-wall surface of the drilled hole at specific layers. The drilling parameters and strength parameters for each layer are shown in Figure 12.

\subsection{Comparison and Analysis of Test and Investigation Results.} To examine the accuracy of the rotary drilling test results, we compared the strength parameters obtained from the indoor test with predicted values. In the depth range of $0.0-0.95 \mathrm{~m}$, UCS was $165.2 \mathrm{kPa}$, shear strength was $525.7 \mathrm{kPa}$, and cohesion was $68.3 \mathrm{kPa}$. The values for the same parameters in the depth range of $1.00-1.45 \mathrm{~m}$ were $96.5,340.5$, and $50.2 \mathrm{kPa}$, respectively, while those in the depth range of $1.50-2.50 \mathrm{~m}$ were $70.4,162.3$, and $20.6 \mathrm{kPa}$, respectively. The

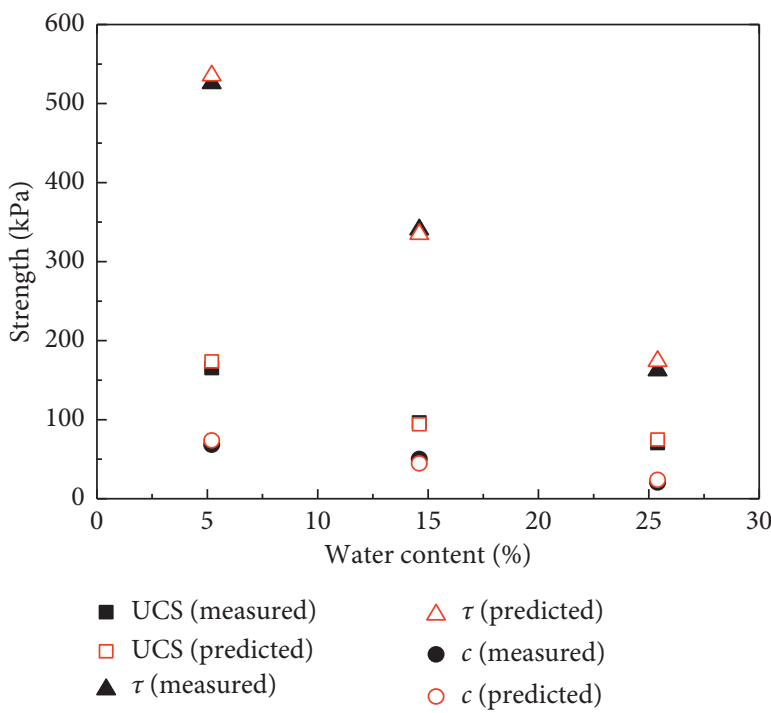

Figure 14: Comparison of test results and predicted values.

indoor test results and the calculated values based on the fitting equations are compared in Figure 14. It can be concluded that when water content was $5.2 \%$ and $25.4 \%$, the predicted values were higher than the test results. Conversely, for water content of $14.6 \%$, the predicted values were lower than the test results. The reason for this is that the water content of the silty clay used in the field test differed 
from that $(4.8 \%, 14.8 \%$, and $24.9 \%)$ used to deduce the fitting equation. Because the strength parameters decrease with increasing water content, when the actual water content of the silty clay is lower than that used for the fitting equation deduction, the predicted values will be smaller than the test results, and vice versa. Overall, the test results showed good agreement with the predicted values with all errors less than $5 \%$. This proves it is feasible to use rotary drilling parameters for the prediction of soil strength parameters. Under the premise that water content is taken into consideration, the deduced fitting equations could be applied to real engineering calculations.

\section{Conclusions}

In this paper, using silty clay as an example case, we applied theoretical analysis, indoor tests, and field application to reveal the quantitative relationships between propulsion and UCS, between torque and cohesion, and between torque and shear strength. Based on the derived findings, we concluded the following:

(1) It is feasible to use rotary drilling parameters to calculate soil strength parameters. While taking water content into consideration, the calculated soil strength parameters could serve as a reference for real engineering projects.

(2) For a situation with constant soil type and given physical parameters, geometric parameters of drill bit and rod, drilling speed, and revolution speed, we can assume that torque is used mainly to overcome shear stress, while propulsion is used mainly to overcome UCS. This assumption can simplify complex mechanical models, and under such a premise, rotary drilling parameters for silty clay (torque and propulsion) are linearly proportional (correlation coefficients are all great than 0.85 ) to UCS, shear strength, and cohesion.

(3) When using drilling parameters to obtain silty clay strength parameters, the results depend on water content. When the actual water content is lower than that used for deducing the quantitative relationship, the obtained value is smaller than the indoor test result.

(4) The quantitative relationship presented in this paper is appropriate for silty clay, especially with water content in the range of $5.0 \%-25.0 \%$. The accuracy of the derived quantitative relationships could be improved by further calibration through field applications.

\section{Data Availability}

The data used to support the findings of this study are available from the corresponding author upon request.

\section{Conflicts of Interest}

The authors declare that they have no conflicts of interest.

\section{Acknowledgments}

This work was supported by the National Natural Science Foundation of China (project nos. 51504029 and 51774048), Beijing Municipal Excellent Talents Foundation (project no. 2017000021223ZK04), Fundamental Research Funds for the Central Universities (project no. FRF-BD-19-004A).

\section{References}

[1] W. Wieder, S. Shoop, L. Barna, T. Franz, and C. Finkenbiner, "Comparison of soil strength measurements of agricultural soils in Nebraska," Journal of Terramechanics, vol. 77, pp. 31-48, 2018.

[2] Y. Nishimatsu, "The mechanics of rock cutting," International Journal of Rock Mechanics and Mining Sciences \& Geomechanics Abstracts, vol. 9, no. 2, pp. 261-270, 1972.

[3] I. Nakajima and S. Kinoshita, "Theoretical studies on cutting force of rock," Journal of the Mining Institute of Japan, vol. 95, no. 1092, pp. 49-55, 1979.

[4] E. Detournay and P. Defourny, "A phenomenological model for the drilling action of drag bits," International Journal of Rock Mechanics and Mining Sciencese Geomechanics Abstracts, vol. 29, no. 1, pp. 13-23, 1992.

[5] Y. Nishimatsu, "Theories of rock cutting," Comprehensive Rock Engineering: Principles, Practice \& Projects, Oxford Pergamon Press, New York, NY, USA, 1993.

[6] Z. Q. Yue, C. F. Lee, K. T. Law, and L. G. Tham, "Automatic monitoring of rotary-percussive drilling for ground characterization-illustrated by a case example in Hong Kong," International Journal of Rock Mechanics and Mining Sciences, vol. 41, no. 4, pp. 573-612, 2004.

[7] S. Okubo, K. Fukui, and W. Chen, "Size and shape of TBM debris estimated by the nishimatsu's cutting-resistance equation," The Open Civil Engineering Journal, vol. 4, no. 1, pp. 88-95, 2010.

[8] R. K. Guo, C. Feng, Z. J. Li, J. Y. Qiao, and S. H. Li, “Theoretical and experimental studies on relationship between working parameters of cone drill and rock strengths," Chinese Journal of Geotechnical Engineering, vol. 38, no. 7, pp. 12211229, 2016.

[9] B. Mirabile, "Geologic features prediction using roof bolter drilling parameters," Master thesis, West Virginia University, Morgantown, WV, USA, 2003.

[10] S. Kahraman, J. Rostami, and A. Naeimipour, "Review of ground characterization by using instrumented drills for underground mining and construction," Rock Mechanics and Rock Engineering, vol. 49, no. 2, pp. 585-602, 2016.

[11] R. Ghosh, A. Gustafson, and H. Schunnesson, "Development of a geological model for chargeability assessment of borehole using drill monitoring technique," International Journal of Rock Mechanics and Mining Sciences, vol. 109, pp. 9-18, 2018.

[12] T. Richard, Determination of Rock Strength from Cutting Tests, University of Minnesota, Minneapolis, MN, USA, 1999.

[13] E. Detournay, T. Richard, and M. Shepherd, "Drilling response of drag bits: theory and experiment," International Journal of Rock Mechanics and Mining Sciences, vol. 45, no. 8, pp. 1347-1360, 2008.

[14] P. Rai, H. Schunesson, P.-A. Lindqvist, and U. Kumar, "An overview on measurement-while-drilling technique and its scope in excavation industry," Journal of The Institution of Engineers (India): Series D, vol. 96, no. 1, pp. 57-66, 2015.

[15] A. Naeimipour, J. Rostami, I. S. Buyuksagis, and O. Frough, "Estimation of rock strength using scratch test by a miniature 
disc cutter on rock cores or inside boreholes," International Journal of Rock Mechanics and Mining Sciences, vol. 107, pp. 9-18, 2018.

[16] H. Schunnesson, "Rock characterisation using percussive drilling," International Journal of Rock Mechanics and Mining Sciences, vol. 35, no. 6, pp. 711-725, 1998.

[17] S. Kahraman, C. Balc1, S. Yazıc1, and N. Bilgin, "Prediction of the penetration rate of rotary blast hole drills using a new drillability index," International Journal of Rock Mechanics and Mining Sciences, vol. 37, no. 5, pp. 729-743, 2000.

[18] N. Bilim, "Determination of drillability of some natural stones and their association with rock properties," Scientific Research and Essays, vol. 6, no. 2, pp. 382-387, 2011.

[19] O. Saeidi, S. R. Torabi, and M. Ataei, "Development of a new index to assess the rock mass drillability," Geotechnical and Geological Engineering, vol. 31, no. 5, pp. 1477-1495, 2013.

[20] Z. Q. Yue, "Drilling process monitoring for refining and upgrading rock mass quality classification methods," Chinese Journal of Rock Mechanics and Engineering, vol. 33, no. 10, pp. 1977-1996, 2014.

[21] R. Leung and S. Scheding, "Automated coal seam detection using a modulated specific energy measure in a monitorwhile-drilling context," International Journal of Rock Mechanics and Mining Sciences, vol. 75, pp. 196-209, 2015.

[22] H. Schunnesson, H. Falksund, A. Gustafson, M. Danielsson, and R. Ghosh, "Assessment of rock mass quality using drill monitoring technique for hydraulic ITH drills," International Journal of Mining and Mineral Engineering, vol. 8, no. 3, pp. 169-186, 2017.

[23] Z. Li and K.-I. Itakura, "An analytical drilling model of drag bits for evaluation of rock strength," Soils and Foundations, vol. 52, no. 2, pp. 216-227, 2012.

[24] J. Rojek, "Discrete element modelling of rock cutting," Computer Methods in Materials Science, vol. 7, no. 2, pp. 224-230, 2007.

[25] J. Mateus, N. F. Saavedra, Z. C. Carrillo, and D. Mateus, "Correlation development between indentation parameters and unconfined compressive strength for colombian sandstones," CT\&F-Ciencia Tecnología y Futuro, vol. 3, no. 3, pp. 125-135, 2007.

[26] ASTM, Annual Book of ASTM Standards: Soils and Rock Division, American Society for Testing \& Materials, West Conshohocken, PA, USA, 1998.

[27] X. F. Lv, H. Y. Zhou, and L. M. Xu, "Study on the quantitative relationship between soil in situ strength and drilling parameters," Environmental Earth Sciences, vol. 77, no. 12, 2018.

[28] E. T. Selig and R. S. Ladd, "Preparing test specimens using undercompaction," Geotechnical Testing Journal, vol. 1, no. 1, pp. 16-23, 1978.

[29] L. Gao, G. H. Hu, Y. H. Chen, Y. J. Hu, and Y. H. Gong, "Triaxial tests clay reinforced by basalt fiber," Chinese Journal of Rock Mechanics and Engineering, vol. 39, no. S1, pp. 198203, 2017.

[30] X. Tang, Development of real-time roof geology detection system using drilling parameters during roof bolting operation, Dept. of Mining Engineering, West Virginia University, Morgantown, WV, USA, Ph.D. Dissertation, 2004.

[31] K. Huang, J. W. Wan, G. Chen, and Y. Zeng, "Testing study of relationship between water content and shear strength of unsaturated soils," Rock and Soil Mechanics, vol. 33, no. 9, pp. 2600-2604, 2012. 